\title{
HISTORICAL HERITAGE AS A TOURIST RESOURCE: THE CASE OF THE PROVINCE OF CÁDIZ, SPAIN
}

\author{
DIEGO MANUEL CALDERÓN PUERTA \& MANUEL ARCILA GARRIDO \\ University of Cádiz, Spain
}

\begin{abstract}
This article has the purpose of analyzing the tourist situation of the historical heritage in the municipalities of the province of Cádiz, considering the need for this type of offer and the obligation to make changes in the management and planning of these resources. The objective of this study is to analyze the tourist use of heritage, its perception by society and the proposal for improvements. All the results presented are the product of a more extensive preliminary research on tourism in the province carried out at the University of Cádiz (Spain). The tourist functionality of historical assets has been studied through the use of different tools that combine the quantitative with the qualitative. At the provincial level, a total of 1,049 assets have been documented, representing an average of 23.84 assets per municipality. With the results obtained, a SWOT has been designed to facilitate the elaboration of proposals and conclusions, whose purpose is to redefine the planning and management of the goods, guaranteeing their sustainability and contribution to the diversification of the tourist offer.

Keywords: historical heritage, cultural tourism, tourism potential, historical heritage management.
\end{abstract}

\section{INTRODUCTION}

Historical heritage assets have played a prominent role in the tourism sector since the beginning of this economic sector. In this sense and by way of example, we can highlight the Grand Tour at the end of the 16th century or the proposals of Tomas Cook already in the 19th century, in which thanks to technical advances, new places are visited (Egypt, Greece, etc.).

The generalized development of these goods as a tourist resource takes place from the 1960s. This process was favored by the need to diversify the tourist offer. In this way the heritage was integrated into the tourism sector, providing a new functionality that contributes to its enhancement and facilitates regional economic development. On the other hand, from the institutional point of view, international organizations such as UNWTO, UNESCO or ICOMOS among others published declarations that sought to consolidate cultural tourism as a new tourist modality [1].

The purpose of this text is the analysis of the management of the historical heritage in the province of Cádiz from the tourist point of view, as well as the study of its potential and perception, so as to facilitate the collection of data that reflect its strengths, weaknesses and The proposal for improvements. The general hypothesis that arises is the need to make improvements in management, as a way of obtaining a more effective planning of these resources.

From the methodological point of view, quantitative and qualitative techniques have been used that offer an integral vision on the tourist use of the historical heritage. In the first place, there has been a brief exposition on the tourist management of the patrimony, later to carry out an analysis on the tourist functionality using web information. Secondly, a potential model has been used that allows us to know the possibilities of tourism development in the region and its spatial distribution. Third, a survey has been carried out at the provincial level on the degree of knowledge and perception of these resources. In the final considerations, a simple SWOT analysis has been used to improve the management and planning of historical heritage as tourist attractions. 


\section{TOURISM HERITAGE MANAGEMENT}

The integration of historical heritage within the tourism sector has enabled the conservation and diversification of uses of goods, while expanding the tourism offer, new tourist profiles appear and in general, has led to increased interest in culture as tourist experience [2].

The tourist use of heritage requires proper planning and management that guarantees its sustainability. This follows from the statements of ICOMOS (1999) [3], UNESCO (2015) [4] and the Council of Europe (2018) [5].

We understand tourism management of cultural resources to be "the application of specific knowledge for the conversion of cultural heritage assets into tourist resources" [6]. This knowledge comes from different disciplines such as economics, history etc. requiring actions that encourage the participation of public and private agents as well as citizens. The planning and management so that it has an integral character, not only must be included in the tourism plans, but also, must be contemplated in the territorial planning. Thus. for Troitiño it is necessary "a dynamic and inclusive vision that takes into account the social, cultural, economic, environmental and functional dimensions" [7]. In a synthesized way, cultural management requires:

- Planning: they are the set of actions necessary for the establishment of objectives and the design of lines of action. In recent times, many initiatives have insisted that tourism planning is conditioned by the sustainability of this economic sector. In this sense and by way of example, we can refer to the Horizon 2020 Spanish Tourism Plan in which one "of its objectives was to improve the sustainability of the Spanish tourism model, ensuring the quality of the natural environment and applying the concept of sustainability to all tourist decisions" [8].

- Evaluation: it is the study of the potential of the area in which the tourist activity will be developed. In this sense, the cultural heritage, tourist equipment, accessibility, infrastructure, skilled labor, etc. must also be taken into account.

- Conservation and proposal of uses: Preserving the historical heritage and its enhancement is the main function of its tourism management, as can be seen from the declarations of ICOMOS in 1999 and UNESCO in 2005. Thus, the use proposals must be tourist but also cultural (school programs, events, etc.), so that the goods fulfill an economic and cultural function UNWTO 1993 [9].

From this brief analysis we can conclude that tourism management of cultural heritage represents an opportunity to improve their social perception and also guarantee their participation in the economy by generating resources that allow their conservation.

\section{HISTORICAL HERITAGE IN THE PROVINCE OF CÁDIZ}

To carry out this analysis, a systematic search has been carried out through tourism web pages at the municipal and provincial levels, a qualitative and quantitative analysis reflected in a potential study and, finally, user surveys.

\subsection{Basic characteristics and tourist use}

A total of 1,049 goods [10] have been registered for the 44 municipalities, which means an average of 23.84 goods per municipality. The municipalities with the highest concentration are Jerez de la Frontera, Cádiz and Puerto de Santa María. On the contrary, those with less assets are Torre Alhaquime, Paterna de Rivera and Prado del Rey.

The predominant typology is the religious one (churches, hermitages, convents etc.) with something more than $40 \%$, although the patrimony of civil and military type is also abundant. 
On the other hand, regarding the level of legal protection, according to Law 16/1985 of the Spanish Historical Heritage [11], the following are distinguished:

- Spanish historical heritage: It is the minimum level of protection and integrates all assets of the state (Art. 1).

- General Inventory of Real Estate: formed by goods that "have a remarkable historical, archaeological, scientific, artistic, technical or cultural value, and that have not been declared of cultural interest" (Art. 26). In the province of Cádiz, a total of 409 registered goods have been registered [12].

- Good of cultural interest: by their relevance they are declared by law or royal decree being inventoried in the general register of goods of cultural interest. From the consultation of this database, we have obtained 328 goods included [13].

The distribution by municipalities of the goods present in the general register of goods of cultural interest has been mapped in Fig. 1.

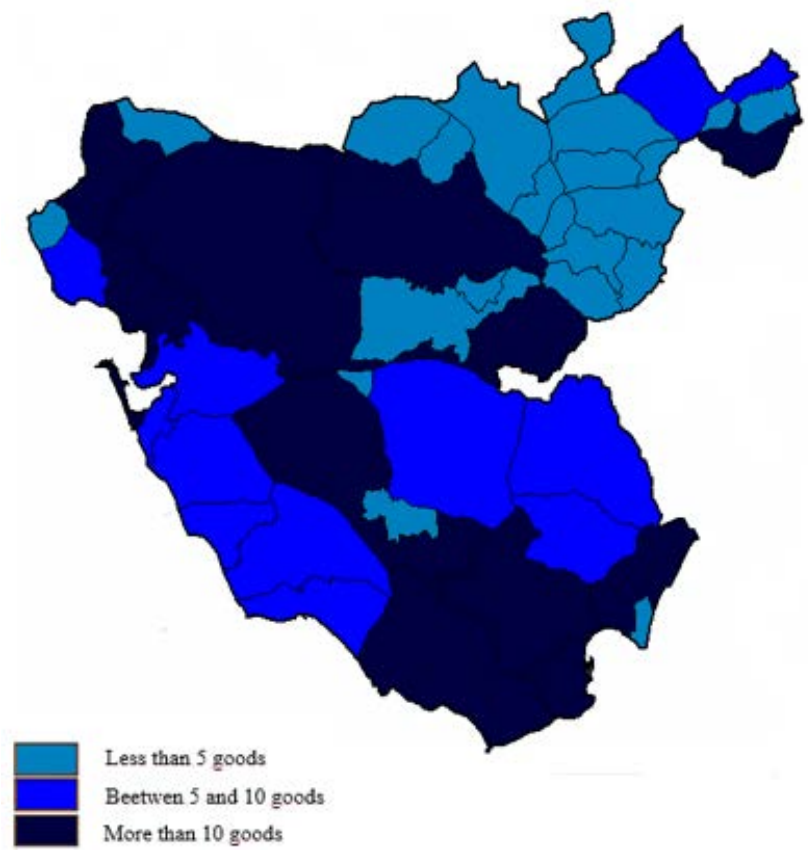

Figure 1: Distribution of gods of cultural interest. (Source: author's own research.)

The second of the parameters analyzed is the consideration of heritage assets as tourist resources. According to the UNWTO, tourism resources are "All those goods and services that, through the activity of man and the means he has, make tourism activity possible and satisfy the activities of the demand, and states that, a tourist resource constitutes the existence of a potential set (known or unknown) of material or intangible assets available to man and that can be used through a process of transformation that makes tourism activity possible and meets the needs of demand" [14]. In similar terms, organizations such as Sectur (2005) and SEGITTUR (2012) [15] have been pronounced. Therefore, we have considered as tourist resources all heritage assets that currently have some type of tourist activity. After a 
systematic search through the tourism web pages at local, provincial and regional level, a total of 356 assets are recorded (Fig. 2), which represents $33.93 \%$ of the total assets documented in the province.

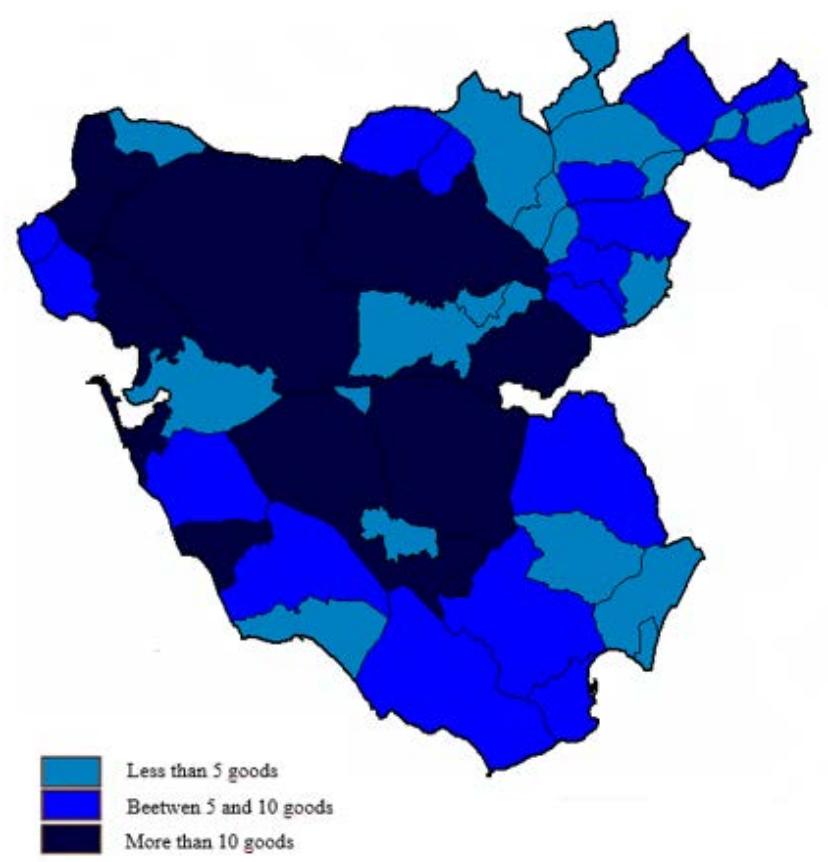

Figure 2: Historical goods with tourist use. (Source: author's own research.)

This tourism promotion is carried out through three strategies:

- Individualized promotion: they represent a total of 118 goods.

- Free visit: those goods that due to their characteristics do not require opening hours (doors, urban walls, etc.) are included. We have accounted for 193 goods being $54.21 \%$ of the total.

- Routes and itineraries: we include in this category the goods that in addition to having an individualized promotion are part of some cultural route or itinerary. They form a total of $23.31 \%$ of the goods analyzed.

Another aspect that we have taken into account in this study is the entrance fee. Of those of whom we have data, $71 \%$ are free. Prices range between 10 euros from the Alcazar of Jerez and the Euro from the convent of the conceptionist nuns (Vejer de la Frontera), so the average cost ranges from 2 euros.

On the other hand, only $31 \%$ have morning and afternoon hours while $23 \%$ have exclusive morning hours. Likewise, only $46 \%$ do not have visiting hours.

The last of the aspects taken into consideration is the use of internet for the dissemination and information of these resources in tourists. Thus, of the 356 goods that have tourist use only $9 \%$ have their own website. On the other hand, only $19 \%$ of the municipalities have exclusive tourism websites, with $68 \%$ of the goods being integrated into municipal websites of a generalist nature. 


\subsection{Tourism potential}

Since the expansion of the 1960s, it has been necessary to carry out studies that allow us to know the tourism potential of an area, in order to promote tourism and know the strategies and measures necessary to consolidate and develop this economic sector. In this sense, a theoretical framework has been developed (Mieczkowski, 1967, Warzynska, 1974, Leno, 1992, Cerezo and Galacho, 2011) that has incorporated methodological proposals, which have become more complex as these studies were developed [16].

We can understand tourism potential as an exhaustive analysis of all those elements that influence tourism activity (climate, landscape, relief, communications, infrastructure, policies, material and intangible heritage, supply, demand, etc.). Analyzed together, they allow data to be obtained and conclusions about the tourist capacity of an area or region.

The concept of potentiality must be open and dynamic, since it must be able to propose a methodology that allows calculating the variables that affect the trends of a sector in constant transformation.

In this case study, we have applied the potential calculation model proposed by Cerezo Medina and Galacho in 2011 [17]. The reason for this choice is to obtain data that allow its introduction into a geographic information system (GIS) to obtain its spatial expression by municipalities. In this way, it is possible to detect those municipalities in which the relationship between tourist infrastructure and historical heritage is highest.

The calculated potential index is summarized in the following eqn:

$$
\mathrm{IPTi}=0.50 * \text { Fri }+0.30 * \text { Fai }+0.20 * \text { Fei. }
$$

Being Fri tourist resources, Fai accessibility and Fei tourist facilities of the municipalities The data have been obtained from the Andalusian Institute of Statistics [18]. From the application of the described methodology, the results presented in Fig. 3 have been obtained.

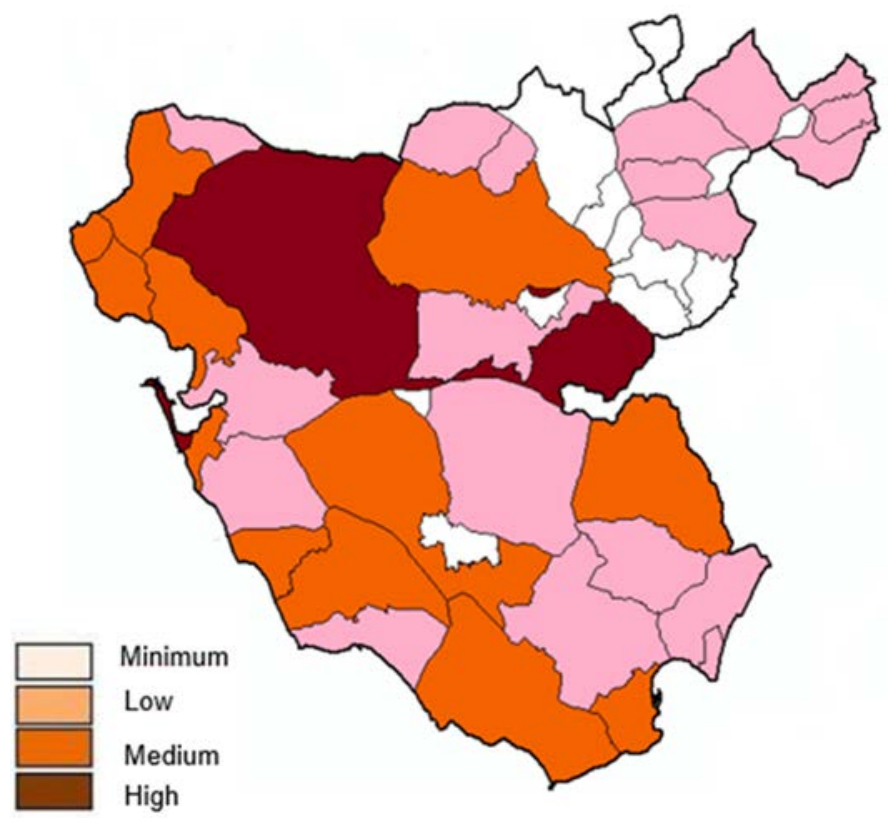

Figure 3: Tourist potential of the province of Cádiz. (Source: author's own research.) 
From the map analysis it is clear that the municipalities with a low potentiality index are those that are located in inland and mountainous areas, which in many cases do not have a developed tourist structure (hotel supply and restoration) or are far from the communication routes (airport or train stations) and cities. On the other hand, municipalities with low and medium potentiality obtain better results due to their historical heritage but also, due to their proximity to coastal or tourist-developed areas.

Finally, the highest potential is obtained by the most populated municipalities in the province and which are also consolidated as a tourist destination.

\subsection{Analysis on perception}

In this section, some of the results of the surveys carried out in May 2019 are presented. 135 tourist surveys were carried out in some tourist offices in the main cities of the province. $62.96 \%$ are women and $37.04 \%$ are men. The ages of the respondents ranged from 21 to 79 years. As regards the place of residence of the people participating in the study, the majority reside in the province of Cádiz, 29.62\% come from other places in Spain and 12.15\% from other European countries (mainly the United Kingdom and France).

Due to the limitations of the article, we will only develop the most interesting results, developing the data obtained in a next work.

The most significant fact is that $68.88 \%$ of respondents have chosen the province of Cádiz because of its climate and natural resources. Despite this first statement, $77.03 \%$ of the respondents had visited at least one historical real estate.

It is interesting to note that only $41.48 \%$ admitted having paid to visit some of the historical assets. On the other hand, we must emphasize that $26.66 \%$ responded affirmatively to the fact that the opening hours of some resources are insufficient.

Regarding the question about whether visitors would pay to visit historical assets, $60.74 \%$ answered affirmatively. However, more than half recognized that they would pay entry based on their typology or historical period.

Finally, there is an important perception between the cultural heritage-tourism relationship. Thus, for $82.86 \%$ of respondents, the main function of historical assets is tourist use.

\section{SWOT AND PROPOSALS}

With the preparation of this SWOT analysis it is intended to capture the conclusions obtained in this study and as a consequence of them, offer some proposals that can improve the planning and management of historical heritage as tourism resources.

The main strengths that are detected are:

- High historical heritage number in the province.

- Typological and thematic diversity of resources.

- Existence of municipalities without assets valued.

- The province has 1,106 million inhabitants who are potential visitors.

- $77.03 \%$ of respondents have visited historical assets.

- $57.77 \%$ of visitors are willing to pay admission.

- $62 \%$ of the goods are free.

- Potential analysis reflects that many municipalities have high capacities to develop cultural tourism activities.

- Existence of an important tourist infrastructure, especially in coastal areas or nearby. 
Weaknesses:

- Existence of many heritage assets without any tourist use.

- Opening hours are not adapted to visits.

- The information in many cases is insufficient and difficult to access.

- Rural and inland areas have little tourist infrastructure.

- Lack of state investment due to public deficit compliance policies.

- The largest volume of visits is concentrated in the large municipalities and the coast.

Opportunities:

- At a distance of two isochronous hours by private vehicle are the provinces of Malaga and Seville with more than 3,581 million inhabitants.

- The tourism sector is expanding as it shows that in 2018 more than $2,152,469$ visitors will spend the night in the Andalusian community [19].

- Existence of national and municipal tourism plans that have historical heritage as an economic resource.

- Greater awareness of the historical heritage as a tourist resource and therefore, greater facilities to diversify the profile of the tourist.

Threats:

- Loss of assets.

- Specialization in sun and beach tourism.

- Lack of widespread financing.

Based on the SWOT analysis, a series of proposals will be made that seek to improve the historical heritage's tourism management so as to guarantee its survival and promote local and sustainable development. For all the above it is proposed:

- Creation of a provincial-scale network that integrates all historical heritage as tourist resources, so that the attention of cultural tourists is captured.

- The network must have a unique website with homogeneous, public and updated information.

- Decrease dependence on public financing with greater participation of the private sector.

- The enhancement or expansion of funds for the tourist use of historical heritage, must have plans that guarantee its sustainability.

- Increase the participation of municipalities in regional and provincial tourism plans, improving collaboration between different administrations.

\section{CONCLUSIONS}

With this study some conclusions have been generated about the tourism model that currently represents historical heritage. In the short term, the management of these goods should be transformed so that they are better integrated into the tourist circuits (extension of schedules, integration into tourist routes and itineraries, improvement of their presence in the network, etc.). These changes would allow, in the medium or long term, to expand their influence on sustainable local development associated with other services (shops, hotels, etc.).

Citizen collaboration in this aspect is important since citizens must be made aware of the value of heritage as a way of preserving culture and as a tourist resource. Tourism 
planning of many of the goods must be improved as seen in the analyzes offered. The tourist potential of the region does not translate in many cases into proper use as it is intuited from the results of monuments without tourist functionality or with little activity (reduced hours, lack of presence on the web etc.). On the other hand, it is evident that for the tourist promotion of heritage the expansion of the hotel offer is necessary, as well as the improvement of communications.

It is necessary the existence of coordinated measures that involve administration, private sector and citizens, in order to facilitate the enhancement of the historical heritage and the diversification of the tourist offer. The results obtained would reaffirm these conclusions.

\section{REFERENCES}

[1] Morère Molinero, N., Paving the way in cultural tourism. Methaodos. Revista de Ciencias Sociales, 5(1), pp. 4-8, 2017.

[2] González Santacruz, F. \& López Guzmán, T., Cultural Heritage as a factor of tourism development: A case Study in the city of Córdoba. Arbor, 193(786), a421, 2017.

[3] ICOMOS, Carta Internacional Sobre Turismo Cultural. La Gestión del Turismo en los sitios con Patrimonio Significativo, 1999.

[4] UNESCO, World heritage and tourism in a changing climate, 2015.

[5] Council of Europe, Communication from the Commission to the European Parliament, The Council, The European Economic and Social Committee and the Committee of the Regions. A new European Agenda for culture, 2018.

[6] Velasco González, M., Tourism management and cultural heritage: Approaches to sustainable cultural tourism development. Cuadernos De Turismo, 23, pp. 237-254. 2009.

[7] Troitiño Vinuesa, M.A. \& Troitiño Torralba, L., Territorial view of heritage and tourism sustainability. Boletín de la Asociación de Geógrafos Españoles, 78, pp. 212244. 2018.

[8] Plumed Lasarte, M., Gómez Bruna, D. \& Martín Luque, C., Tourism planning, promotion and environmental sustainability: The case of Spain. Retos Revista de Ciencias de la Administración y Economía, 15(8), pp. 7-17, 2018.

[9] UNWTO, General assembly documents, 1993.

[10] Junta de Andalucía, Database of the Andalusian Historical Heritage Institute. www.iaph.es/web/portal/buscador/index.jsp?query=bdi.

[11] Spanish government, Law 16/1985 of the Spanish historical heritage. 1985.

[12] Spanish government, Real estate database. www.culturaydeporte.gob.es/bienes/ cargarFiltroBienesInmuebles.do?layout $=$ bienesInmuebles \& cache $=$ init\&language $=$ es.

[13] Spanish government, Inventory of goods of cultural interest. www.culturaydeporte.gob.es/cultura-mecd/areas-cultura/patrimonio/bienesculturales-protegidos.html.

[14] UNWTO, Introducción al turismo. 1978.

[15] Jean Camara, C. \& Morcate Labrada, F., Methodology for the identification, classification and assessment of territorial tourist resources of the city center of Fortde-France. Arquitectura y Urbanismo, XXXV(1), pp. 58-98, 2014.

[16] Covarrubias, R., Evaluación del Potencial en Municipios Turísticos a Través de Metodologías Participativas. El Caso de los Municipios de la Zona Norte de Colima. Mexico, University of Colima, 2015.

[17] Cerezo Medina, A. \& Galacho J., A GIS-based proposal for evaluating the potential of the territory for ecotourism and adventure tourism activities: An application to Sierra de Las Nieves (Málaga, Spain). Investigaciones Turísticas, 1, pp. 134-147, 2011. 
[18] Andalusian Institute of Statistics, www.juntadeandalucia.es/institutodeestadisticaycartografia/temas/est/tema_turismo.h tm.

[19] Diputación de Cádiz, Patronato de Turismo. www.dipucadiz.es/patronatoturismocadiz/observatorio-turistico/2018. 